\title{
Bibliometria: quinze anos de análise da produção acadêmica em periódicos brasileiros
}

\author{
Henrique César Melo Ribeiro \\ Universidade Federal do Piauí - UFPI, Brasil
}

\section{ORIGINAL}

\begin{abstract}
Resumo
Objetivo. Este artigo tem como objetivo analisar o perfil e o padrão de crescimento da produção acadêmica dos artigos bibliométricos, nos periódicos nacionais da área de Administração, Contabilidade e Turismo (Triênio 2010-2012), durante o período de 1999 a 2013. .

Método. Para isso, utilizaram-se, metodologicamente, as técnicas de análise bibliométrica e de rede social em 366 identificados.

Resultados. Os principais resultados identificaram que as revistas de Administração Contemporânea e de Administração de Empresas foram as mais produtivas; houve crescimento de estudos bibliométricos a partir de 2007; proeminência de artigos publicados em parceria; a Universidade de São Paulo e a Universidade Federal de Santa Catarina foram as Instituições de Ensino Superior com maior produção acadêmica e também se destacaram como as mais centrais deste estudo. Observou-se baixa densidade de rede de coautoria, e das IESs. Os temas: ensino e pesquisa em contabilidade, metodologia científica, ensino e pesquisa em administração, estratégia, contabilidade, contabilidade gerencial, empreendedorismo, controladoria, gestão de custos, gestão de pessoas e marketing, foram os mais publicados em 15 anos de estudos, respectivamente.
\end{abstract}

Palavras-chave

Pesquisa bibliométrica; Periódicos nacionais; Produção acadêmica

\section{Bibliometrics: Fifteen Years of Analysis of Academic Production in Brazilian Journals}

\begin{abstract}
Objective. This article aims to analyze the pattern of growth and the academic production of bibliometric articles in national journals in the field of Management, Accounting and Tourism (2010-2012), during the period 1999-2013.

Method. For this, we used methodological techniques bibliometric analysis and social network in 366 identified.

Results. The main results were: the Journal of Contemporary Management and Journal of Business Administration were the most productive, growth of bibliometric studies from 2007; prominence of articles published in partnership; University of São Paulo and the Federal University of Santa Catarina were HEls with academic production and also stood out as the most central in this study. Observed a low density of co-authoring network, and HEls. And the themes: teaching and research in accounting, scientific methodology, teaching and research in management, strategy, accounting, management accounting, entrepreneurship, controlling, cost management, people management and marketing, were published over 15 years of study respectively.
\end{abstract}

\section{Keywords}

Academic production; Bibliometric research; Brazilian journals

\section{Introdução}

A comunicação por meio das revistas acadêmicas é a forma mais utilizada pelos pesquisadores para difundir os resultados de suas investigações (URBIZAGASTEGUI, 2016). Diante disso, observa-se que, nos últimos anos, há uma preocupação da comunidade acadêmica em conhecer a estrutura intelectual das produções acadêmicas nacionais em várias áreas do conhecimento, e que isso vem se refletindo na produção de diversos estudos sobre diversos assuntos (GRAEML; MACADAR, 2010). A análise bibliométrica é uma das técnicas de pesquisa que tem como foco mensurar, de maneira quantitativa, as publicações científicas de um autor ou Instituição de 
Ensino Superior (IES) em periódicos acadêmicos com seleção arbitrada (SOUZA; RIBEIRO, 2013), por meio de padrões e métodos matemáticos e estatísticos (FRANCISCO, 2011), usando, com isso, seus resultados para elaborar previsões e apoiar tomadas de decisões (BORBA; HOELTGEBAUM; SILVEIRA, 2011). Diante desse panorama, pode-se constatar e entender que a bibliometria é bem-vinda no contexto das investigações, dos mapeamentos, das explorações e análises de diversos temas acadêmicos (VALE; LOPES, 2010).

Estudos dessa natureza foram desenvolvidos em diferentes áreas no Brasil, com destaque para: Accountability (MEDEIROS; CRANTSCHANINOV; SILVA, 2013), Administração (DAVEL; ALCADIPANI, 2003), Avaliação da Qualidade dos Serviços Bancários (ENSSLIN; ENSSLIN; PINTO, 2013), Casos de ensino (FARIA; FIGUEIREDO, 2013), Contabilidade de Custos (CARDOSO; PEREIRA; GUERREIRO, 2007), Contabilidade Gerencial (NASCIMENTO; JUNQUEIRA; MARTINS, 2010), Controladoria (BEUREN; SCHLINDWEIN; PASQUAL, 2007), Ensino e pesquisa em contabilidade (MENDONÇA NETO; RICCIO; SAKATA, 2009; NASCIMENTO; BEUREN, 2011), Estratégia (SARAIVA; CARRIERI, 2009), Finanças (LEAL; ALMEIDA; BORTOLON, 2013; MENDES-DA-SILVA; ONUSIC; GIGLIO, 2013), Franchising (MELO; ANDREASSI, 2010), Gestão Ambiental Empresarial (JABBOUR; SANTOS; BARBIERI, 2008), Gestão de Pessoas (CALDAS; TINOCO, 2004; MASCARENHAS; BARBOSA, 2013), Identidade Organizacional (BEYDA; MACEDO-SOARES, 2010), Inovação (BRANDÃO; BRUNO-FARIA, 2012), Marketing (MAZZON; HERNANDEZ, 2013), Responsabilidade social empresarial (MORETTI; CAMPANARIO, 2009), Sustentabilidade Ambiental (SOUZA; RIBEIRO, 2013), Teoria institucional (GUARIDO FILHO; MACHADO-DA-SILVA; ROSSONI, 2010), Turismo (BRUNELLI et al., 2010) e Visão Baseada em Recursos (RIBEIRO et al., 2012). Além de estudos que realçam temas específicos, os trabalhos de: Francisco (2011), Beuren, Pinto e Zonatto (2012), Kneipp et al. (2013), Ribeiro e Costa (2013) e Teixeira, Nascimento e Antonialli (2013) estudaram especificamente periódicos e ou congressos das áreas de Administração e/ou Contabilidade.

Quanto aos estudos no âmbito internacional, destacam-se os de: Nerur, Rasheed e Natarajan, (2008), Narayanan, Zane e Kemmerer (2011), que fizeram suas respectivas pesquisas sobre a área da estratégia. Acedo, Barroso e Galan (2006) e Hart e Dowell (2011) estudaram, concomitantemente, a Visão Baseada em Recursos. Shi, Sun e Prescott (2011) investigaram o assunto alianças estratégicas. Harris (2009) e Durisin e Puzone (2009), investigaram o assunto governança corporativa. Ressaltam-se também os trabalhos dos autores Ramos-Rodríguez e Ruíz-Navarro (2004) e Robertson (2008) que fizeram estudos bibliométricos apenas sobre um periódico - o Strategic Management Journal.

Contudo, mesmo analisando estudos bibliométricos nacionais e internacionais recentes e até mesmo alguns que não estão em estado da arte, não foi identificado nenhum trabalho, ou até mesmo similar, que tratasse de um estudo bibliométrico da própria temática bibliometria, ou seja, estudos de autores que se propunham a fazer uma bibliometria do próprio tema em questão, com exceção do estudo internacional dos autores Patra, Bhattacharya e Verma (2006) que analisaram os estudos bibliométricos internacionais de 1968 a 2004, por meio das técnicas bibliométricas.

Diante do exposto, este artigo se propõe preencher essa falta de informações sobre a produção acadêmica a respeito de bibliometria. Realça-se, assim, a questão de pesquisa que norteou este estudo: Qual o perfil e a evolução da produção acadêmica dos artigos bibliométricos, nos periódicos nacionais da área de Administração, Contabilidade e Turismo (Triênio 2010-2012), durante o período de 1999 a 2013? O objetivo deste estudo foi: analisar o perfil e o padrão de crescimento da produção acadêmica dos artigos bibliométricos, nos periódicos nacionais da área de Administração, Contabilidade e Turismo (Triênio 2010-2012), durante o período de 1999 a 2013.

Justifica-se analisar a produção acadêmica sobre o tema bibliometria, pela diversidade que este tipo de estudo alcança, ou seja, a amplitude que os estudos bibliométricos podem ter, ao analisar, investigar, explorar e mapear temas diversos, de áreas diversas, fomentando a estrutura intelectual de vários temas, por meio de atributos que podem ser impactantes para a otimização, socialização e divulgação destas temáticas na literatura acadêmica nacional e internacional. Outra justificativa plausível é de que nunca antes tinha sido feito um estudo com este foco no Brasil, mediante um arcabouço de periódicos e, consequentemente, de artigos que contemplam um escopo bem generalizado de temas para as áreas de Administração, Contabilidade e Turismo. Justifica-se também este estudo, pois, contemplará e mensurará várias variáveis que proporcionarão, em todas as suas nuances, a amplitude e importância que a pesquisa bibliométrica têm para a literatura acadêmica nacional. 
Este estudo contribuirá para a melhor compreensão do tema bibliometria em diversas áreas que esta temática pode ser aplicada, como técnica matemática e estatística, propiciando que sejam detectados, por exemplo, quais assuntos são mais trabalhados usando tal técnica e/ou quais temáticas estão sendo menos evidenciadas, podendo ser uma oportunidade de melhor entendimento dos temas esboçados neste estudo, que não foram tão vistos e/ou explorados mediante a análise bibliométrica, que é o tema principal deste estudo. Em suma, este estudo contribuirá para detectar indicadores, tendências e vieses (CARDOSO et al., 2005), da temática bibliometria no meio acadêmico nacional.

\section{Fundamentação teórica}

Esta seção elencará estudos que versaram sobre os conceitos e a Teoria da análise bibliométrica.

\subsection{Conceitos e teoria da bibliometria}

A bibliometria é o estudo dos aspectos quantitativos da produção, disseminação, socialização e evidenciação da informação registrada (MACIAS-CHAPULA, 1998). Contudo, a bibliometria só se iniciou no final dos anos de 1960, pois foi o autor Pritchard (1969) que popularizou o termo bibliometria, que, desde 1922, era conhecida como bibliografia estatística (VANTI, 2002).

Pritchard (1969) usou pela primeira vez o termo bibliometria, desenvolvendo padrões e modelos matemáticos e estatísticos para mensurar os processos de informações, usando seus resultados para elaborar previsões e apoiar tomadas de decisão (MACIAS-CHAPULA, 1998). Já nas décadas de 1970 e 1980, a bibliometria foi constituída como disciplina. Na década de 1990, a disciplina bibliometria, tornou-se técnica de análise padrão para diversas ciências (PATRA; BHATTACHARYA; VERMA, 2006).

Desta disciplina, existem três nomes que embasaram as técnicas da bibliometria, são eles: Bradford, Lotka e Zipf. Cada um destes pesquisadores, podem ser identificados com uma lei específica, respectivamente. As duas primeiras leis em especial, ou seja, as leis de dispersão de Bradford (1934) e de produtividade científica de Lotka (1926) foram marcos iniciais da bibliometria (PATRA; BHATTACHARYA; VERMA, 2006) e, portanto, serão mais discutidas nesta seção.

Em suma, a Lei de Bradford ou Lei de Dispersão, permite, por meio a mensuração da produtividade dos periódicos, estabelecer o núcleo e as áreas de dispersão sobre um determinado tema em um mesmo conjunto de periódicos (VANTI, 2002). Contemplando a Lei de Bradford, ela sugere que à medida que os primeiros estudos sobre um novo tema são escritos, eles são submetidos a uma pequena seleção, por revistas apropriadas, e se aceitos, essas revistas aproximam mais e mais papers, no decorrer do desenvolvimento da temática. Ao mesmo tempo, outras revistas publicam seus primeiros manuscritos sobre o tema. Se o assunto continuar a se aperfeiçoar, surgirão, eventualmente, um núcleo de revistas, que corresponderão as revistas mais produtivas da área, em termos de estudos, sobre o referido tema (BEUREN; SOUZA, 2008). Sendo que este núcleo é calculado assim: o total de artigos deve ser somado e dividido por três. Logo em seguida, observa-se a característica: o grupo com mais artigos, até 1/3 dos artigos, é o núcleo principal ou core do tema analisado. 0 segundo e o terceiro grupos são as extensões (PELEIAS et al., 2010).

Diante do exposto, entende-se que a Lei de Bradford é uma ferramenta especialmente útil para o aperfeiçoamento de políticas de alcance e de rejeite de revistas. É possível aferir a amplitude de determinada área bibliográfica e toda e qualquer fração específica da bibliografia, no todo (BEUREN; SOUZA, 2008).

Realçam-se os estudos de: Cardoso et al. (2005), Beuren e Souza (2008), Peleias et al. (2010), Peleias et al. (2013), Souza e Ribeiro (2013), que enfatizaram a Lei de Bradford em seus resultados.

A Lei de Lotka, ou Lei do Quadrado Inverso, assinala para o calculo da produtividade dos pesquisadores, mediante um modelo de distribuição tamanho-frequência dos diversos pesquisadores em um conjunto de artigos, por exemplo (VANTI, 2002). Em outras palavras, constata-se que a produtividade, na forma de artigos publicados, é considerada como a parte em que diferentes autores contribuem para o aperfeiçoamento da ciência, e que foi estudada por Lotka (1926), constitui os fundamentos da lei do quadrado inverso, afirmando que o número de pesquisadores que fazem $n$ contribuições num determinado campo do conhecimento científico é, aproximadamente, 1/n2 daqueles que fazem um só aporte, e que a proporção daqueles que fazem uma única 
contribuição é de mais ou menos 60\% (Urbizagastegui, 2008). Ou seja, a Lei de Lotka pode ser calculada por meio da fórmula destacada na seguinte equação (RICCIO; MENDONÇA NETO; SAKATA, 2007).

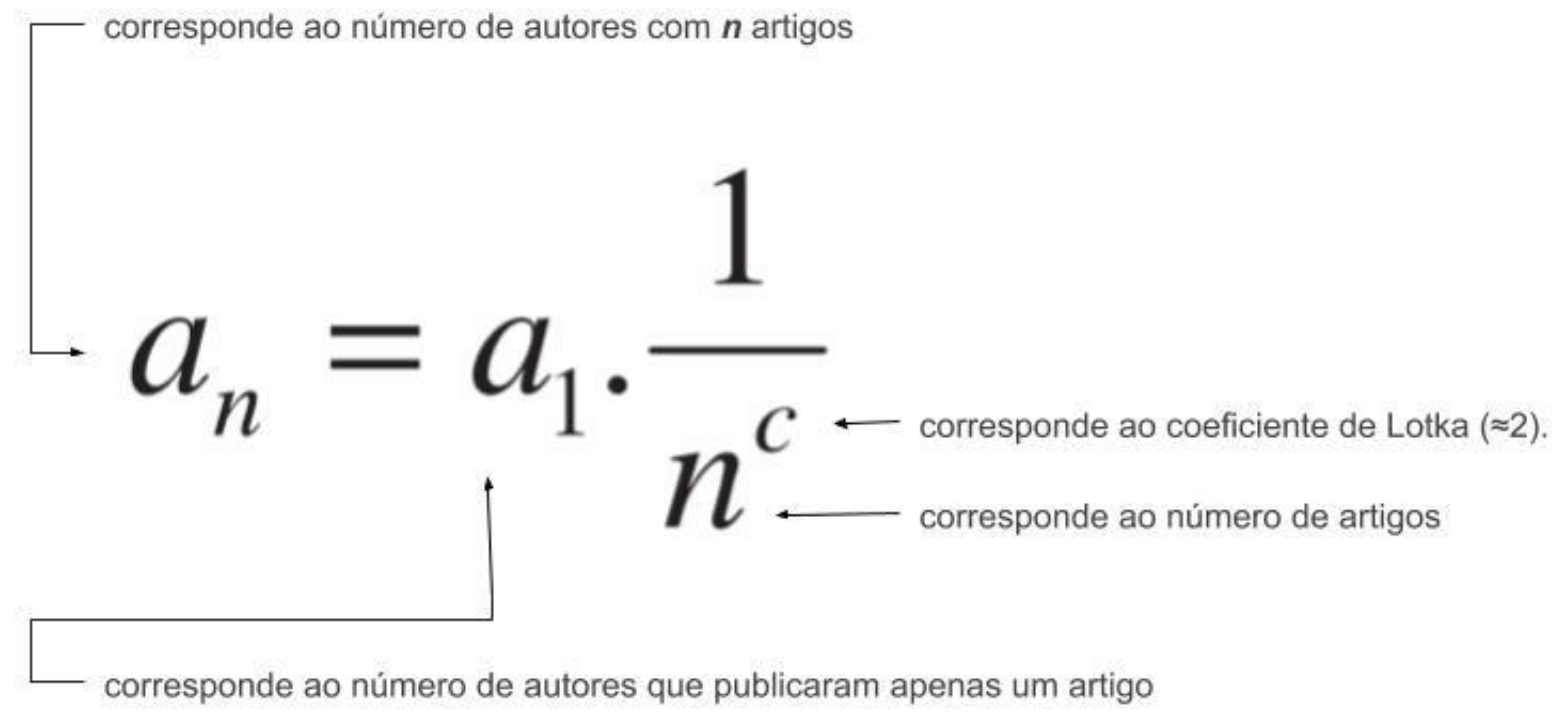

Desde 1926, época em que Lotka estabeleceu esse modelo, muitas pesquisas têm sido realizadas para estudar a produtividade dos pesquisadores em distintas disciplinas. Realçam-se aqui, em especial nas áreas de Administração, Contabilidade e Turismo, publicações mais recentes que tiveram este foco: Riccio, Mendonça Neto e Sakata (2007), Moretti e Campanario (2009), Rossoni e Hocayen-da-Silva (2009) e Matos et al. (2012). Sendo assim, este estudo abordará esse padrão de comportamento de literatura sobre a Lei de Lotka e analisará a produtividade dos autores que publicaram sobre o tema bibliometria, em 15 anos de estudos, nas revistas nacionais do Qualis Capes (2014) do triênio (2010-2012).

Já a Lei de Zipf, também conhecida como Lei do Mínimo Esforço, consiste em mensurar a frequência do aparecimento das palavras em vários documentos, criando uma lista ordenada de termos de uma determinada temática (VANTI, 2002). Os trabalhos de: Francisco (2011) e Gomes e Scarpin (2012), destacam a Lei de Zipf em suas respectivas análises. Portanto, este estudo foi conduzido com base nessas três leis.

Em suma, verifica-se e contempla-se a importância da Bibliometria para conhecer, de maneira analítica e aprofundada, uma determinada área do conhecimento científico (LEITE FILHO, 2008), sendo que isso é fundamental para promover, aprimorar, desenvolver, socializar, difundir e evidenciar temas já legitimados, temáticas emergentes e assuntos embrionários, contribuindo para que a estrutura intelectual, em especial, na área de Administração, Contabilidade e Turismo que é o foco deste estudo, cresça e evolua por meio destas publicações, mediante, pesquisadores sêniores e novos, acarretando a criação e/ou aperfeiçoamento de grupos de estudos, além de influenciar, de certa maneira, o surgimento de novos congressos, seminários e periódicos de qualidade que congreguem artigos de igual valor acadêmico e científico.

\section{Procedimentos metodológicos}

O objetivo deste estudo foi analisar o perfil e o padrão de crescimento da produção acadêmica dos artigos bibliométricos, nos periódicos nacionais da área de Administração, Contabilidade e Turismo (Triênio 2010-2012), durante o período de 1999 a 2013. Para que isso ocorra, optou-se por usar as técnicas de análise bibliométrica (CARDOSO et al., 2005) e de rede social (ROSSONI; GUARIDO FILHO, 2009).

A bibliometria é uma técnica de análise de pesquisa que estuda publicações em livros, relatórios e em artigos (FERREIRA, 2011) para quantificar, analisar e avaliar a produção acadêmica científica de temas (RAMOSRODRÍGUEZ; RUÍZ-NAVARRO, 2004), sendo, portanto, adequada ao objetivo geral deste estudo. Diante disso, justifica-se o uso da análise bibliométrica por ela conseguir cobrir períodos de tempo prolongados, viabilizando, 
com isso, a identificação, socialização e evidenciação de informações importantes e que são inerentes à temática investigada (NERUR; RASHEED; NATARAJAN, 2008).

No que se refere a rede social, ela caracteriza-se por elencar um conjunto de atores e as possíveis relações entre eles (WASSERMAN; FAUST, 1994). Como evidenciado anteriormente, será usado a análise de redes sociais, sobretudo, a análise de coautorias (RAMOS-RODRÍGUEZ; RUÍZ-NAVARRO, 2004; NERUR; RASHEED; NATARAJAN, 2008). Pode-se entender que a coautoria de artigos publicados é o fenômeno da interação humana em comunidades acadêmicas científicas, sendo que esta conexão existe quando dois ou mais pesquisadores publicaram, pelo menos, um artigo em conjunto (VANZ, 2009).

Conhecendo as redes de coautoria deste estudo, será possível compreender como os autores estabelecem parcerias e com quem colaboram, no que tange as pesquisas sobre bibliometria. Além disso, permitirá comparar também, maneira direta e indiretamente, as informações contempladas pela área de Administração, Contabilidade e Turismo, mediante as demais redes sociais das Instituições de Ensino Superior (IESs), e estados e países em conjunto, a fim de identificar possíveis especificidades e mesmo orientações conceituais dos diversos fenômenos e temas publicados nos artigos sobre bibliometria. Contudo, realça-se que esta dinâmica será realizada e visualizada por meio dos relacionamentos entre os atores (MELLO; CRUBELLATE; ROSSONI, 2010), que neste estudo serão retratados por meio das redes de coautoria, redes das IESs e redes dos estados e países em conjunto.

Para analisar o perfil e o padrão de crescimento da produção acadêmica do tema bibliometria, nos periódicos nacionais da área de Administração, Contabilidade e Turismo, foi realizada uma coleta de dados em artigos nacionais publicados no Qualis da Capes (2014) triênio (2010-2012) durante o período de 1999 a 2013, o que correspondeu a um levantamento longitudinal de 15 anos. Os dados foram coletados dos respectivos sites das revistas objetivo de estudo (Tabela 1).

Tabela 1 - Classificação dos periódicos, triênio (2010-2012).

\begin{tabular}{|c|c|c|}
\hline Revista & ISSN & Nota \\
\hline Brazilian Administration Review & $1807-7692$ & A2 \\
\hline Brazilian Business Review & $1807-734 X$ & A2 \\
\hline Gestão \& Produção & $1806-9649$ ou $0104-530 x$ & A2 \\
\hline RAC Eletrônica & $1981-5700$ & $\mathrm{~A} 2$ \\
\hline Revista de Administração Contemporânea & $1415-6555$ ou $1982-7849$ & A2 \\
\hline RAE Eletrônica & $1676-5648$ & A2 \\
\hline Revista de Administração de Empresas & 0034-7590 ou 2178-938X & A2 \\
\hline RAUSP-e & $1983-7488$ & $\mathrm{~A} 2$ \\
\hline Revista Brasileira de Economia & $0034-7140$ & $\mathrm{~A} 2$ \\
\hline Revista Contabilidade \& Finanças & $1519-7077$ ou $1808-057 X$ & $\mathrm{~A} 2$ \\
\hline Revista de Administração da USP & 0080-2107 ou 1984-6142 & $\mathrm{A} 2$ \\
\hline Revista de Administração Pública & $0034-7612$ & $\mathrm{~A} 2$ \\
\hline Revista Base & $1984-8196$ ou $1807-054 X$ & B1 \\
\hline Cadernos Ebape & $1679-3951$ & B1 \\
\hline Contabilidade Vista \& Revista & $0103-734 X$ & B1 \\
\hline Contexto Internacional & $0102-8529$ & B1 \\
\hline Economia Aplicada & $1413-8050$ & B1 \\
\hline
\end{tabular}


Tabela 1 - Classificação dos periódicos, triênio (2010-2012) - continuação.

\begin{tabular}{|c|c|c|}
\hline Revista & ISSN & Nota \\
\hline Economia e Sociedade & $0104-0618$ & B1 \\
\hline Economia Global e Gestão & $0873-7444$ & B1 \\
\hline Estudos Econômicos & $0101-4161$ & B1 \\
\hline Faces: Revista de Administração & $1517-8900$ ou $1984-6975$ & B1 \\
\hline Gestão \& Regionalidade & $1808-5792$ ou $2176-5308$ & B1 \\
\hline Produção & $1980-5411$ ou $0103-6513$ & B1 \\
\hline Nova Economia & $0103-6351$ & B1 \\
\hline Revista de Administração e Inovação & $1809-2039$ & B1 \\
\hline Revista de Administração Mackenzie & $1518-6776$ ou $1678-6971$ & B1 \\
\hline Revista Eletrônica de Administração & $1413-2311$ ou $1980-4164$ & B1 \\
\hline Revista Brasileira de Finanças & $1679-0731$ ou $1984-5146$ & B1 \\
\hline Revista Brasileira de Gestão de Negócios & 1983-0807 ou 1806-4892 & B1 \\
\hline Revista Contemporânea de Contabilidade & $2175-8069$ ou $1807-1821$ & B1 \\
\hline Revista de Administração da UFSM & $1983-4659$ & B1 \\
\hline Revista de Administração da Unimep & $1679-5350$ & B1 \\
\hline Revista de Ciências da Administração & 2175-8077 ou 1516-3865 & B1 \\
\hline Revista de Contabilidade e Organizações & $1982-6486$ & B1 \\
\hline Revista de Economia Contemporânea & $1415-9848$ & B1 \\
\hline Revista de Economia Política & 0101-3157 ou $1809-4538$ & B1 \\
\hline Revista Universo Contábil & $1809-3337$ & B1 \\
\hline Contabilidade, Gestão e Governança & 1984-3925 & B2 \\
\hline Contextus & $1678-2089$ & B2 \\
\hline Enfoque: Reflexão Contábil & $1517-9087$ & B2 \\
\hline Gestão \& Planejamento & $2178-8030$ & B2 \\
\hline Gestão \& Sociedade & $1980-5756$ & B2 \\
\hline Internext & $1980-4865$ & B2 \\
\hline Organizações em Contexto & $1809-1040$ ou $1982-8756$ & B2 \\
\hline Perspectivas Contemporâneas & $1980-0193$ & B2 \\
\hline Pretexto & $1517-672 X$ ou $1984-6983$ & B2 \\
\hline Revista de Administração, Contabilidade e Economia & $1678-6483$ ou $2179-4936$ & B2 \\
\hline Revista Brasileira de Estratégia & $1983-8484$ & B2 \\
\hline Revista Eletrônica de Ciência Administrativa & $1677-7387$ & B2 \\
\hline Revista de Gestão da USP & $2177-8736$ ou $1809-2276$ & B2 \\
\hline Revista Alcance & 1983-716X & B2 \\
\hline
\end{tabular}


Tabela 1 - Classificação dos periódicos, triênio (2010-2012) - continuação.

\begin{tabular}{|c|c|c|}
\hline Revista & ISSN & Nota \\
\hline Revista Ambiente Contábil & $2176-9036$ & B2 \\
\hline Revista de Educação e Pesquisa em Contabilidade & $1981-8610$ & B2 \\
\hline Revista Economia \& Gestão & 1984-6606 & B2 \\
\hline Revista Iberoamericana de Estratégia & $2176-0756$ & B2 \\
\hline Revista Pensamento Contemporâneo em Administração & $1982-2596$ & $\mathrm{~B} 2$ \\
\hline Revista de Gestão Organizacional & $1806-6720$ ou $1983-6635$ & B2 \\
\hline Revista de Gestão Social e Ambiental & $1981-982 X$ & $\mathrm{~B} 2$ \\
\hline Sociedade, Contabilidade e Gestão & $1982-7342$ & B2 \\
\hline
\end{tabular}

Fonte: Capes (2014)

O critério utilizado para a busca e seleção dos artigos relevantes nos periódicos brasileiros incluídos na base de dados da Capes (2014) envolveu as seguintes palavras-chave: Bibliometria e Bibliometrics, localizadas não simultaneamente, para que fossem selecionados todos os manuscritos que tivessem ao menos uma das palavras-chave anteriormente evidenciada: no título, no resumo e nas palavras-chave dos papers desta pesquisa. Este procedimento permitiu identificar 59 periódicos que publicaram artigos bibliométricos sobre diversos temas. A mostra final foi composta por 366 artigos publicados no período 1999-2013.

Estes 366 manuscritos foram analisados de maneira quantitativa, conforme as seguintes variáveis: (I) periódicos e os de maior destaque; (II) evolução das pesquisas sobre bibliometria; (III) características de autoria; (IV) autores; (V) redes de coautoria; (VI) redes de coautoria (degree); (VII) IESs; (VIII) rede das IESs; (IX) rede das IESs (degree); (X) redes dos estados e países (degree); (XI) palavras-chave; e (XII) temas. As informações relevantes sobre cada artigo foram capturadas utilizando o software Bibexcel e as representações gráficas das redes foram feitas usando os softwares UCINET 6 for Windows, Microsoft Excel 2007 e Wordle.net..

\section{Análise e discussão dos resultados}

A finalidade desta seção foi mobilizar a análise bibliométrica e de rede social dos 366 artigos bibliométricos publicados nos periódicos brasileiros de 1999 a 2013.

A Figura 1 contempla os 59 periódicos analisados neste estudo, com ênfase aos 13 que mais publicaram artigos sobre estudos bibliométricos de 1999 a 2013.

Analisando a Figura 1, enfatiza-se a Revista de Administração Contemporânea como o periódico que mais publicou estudos relacionados a bibliometria, com 28 artigos publicados. Em seguida realça-se a Revista de Administração de Empresas, com 24 publicações. Comprova-se a importância destes dois periódicos por meio destes achados, pois, são consideradas as mais tradicionais revistas acadêmicas de Administração do Brasil, juntamente com a Revista de Administração da USP (GRAEML; MACADAR, 2010), que, neste trabalho, publicou nove artigos relacionados a estudos bibliométricos. 


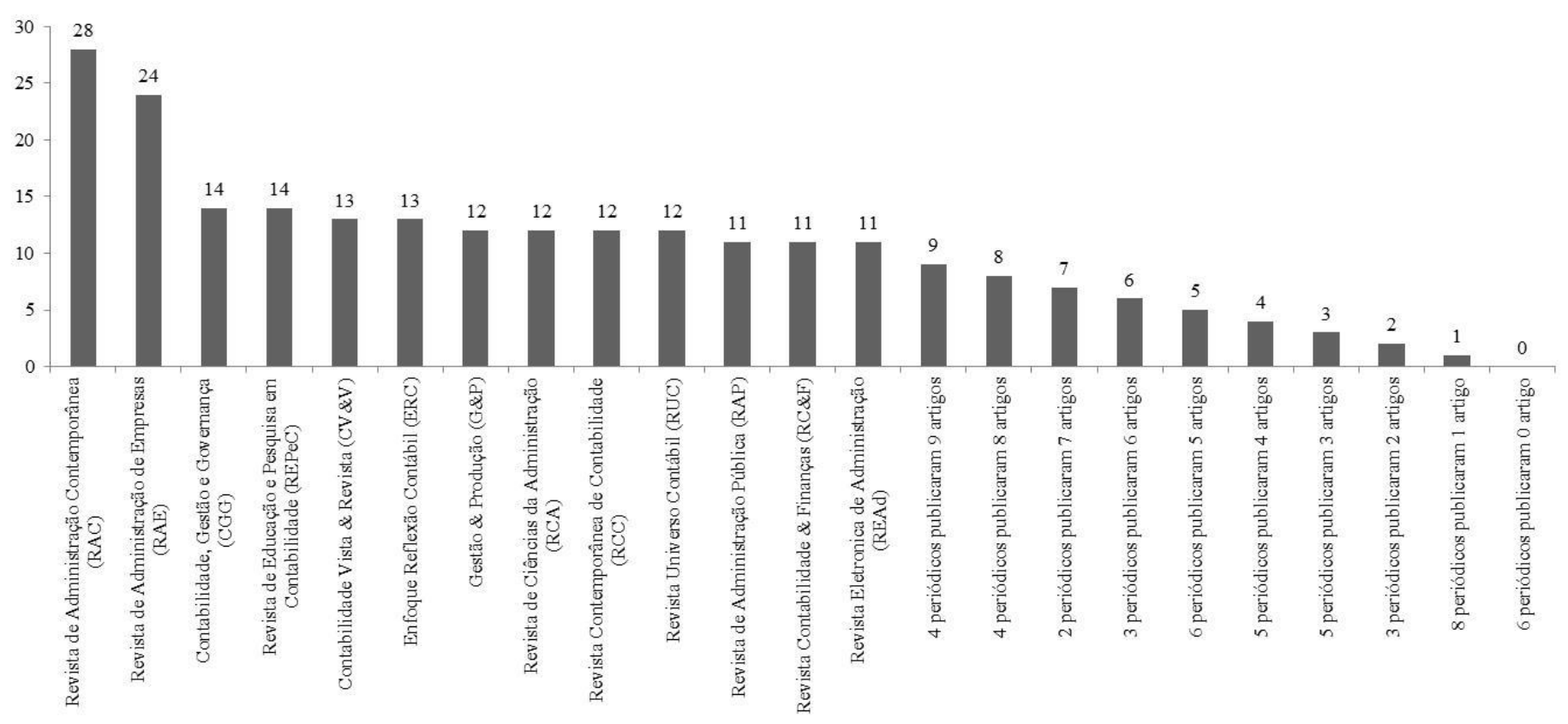

Figura 1: Periódicos

Fonte: Dados da pesquisa

Ainda destacando a importância das revistas RAC e RAE nesta pesquisa, evidenciam-se os estudos bibliométricos dos autores: Cardoso et al. (2005), Graeml e Macadar (2010), Francisco (2011), Ribeiro et al. (2012), Souza e Ribeiro (2013), que ressaltam a importância destas duas revistas para a literatura acadêmica nacional, na área de Administração.

Ainda observando a Figura 1, contemplam-se as revistas: CGG, REPeC, CV\&V, ERC, G\&P, RCA, RCC, RUC, RAP, RC\&F e REAd, com 14, 14, 13, 13, 12, 12, 12, 12, 11, 11 e 11 artigos publicados, respectivamente. Diante desses dados, é interessante divulgar que, entre as 13 revistas mais profícuas, sete são da área contábil e seis da área de administração, mostrando assim o equilíbrio entre as áreas nas publicações de artigos bibliométricos. E entre estes 13 periódicos, cinco têm conceito A2, cinco com conceito B1 e três no extrato B2 de acordo com o triênio (2010-2012) da Capes (2014).

Em suma, tais informações mostram que os estudos bibliométricos permeiam, de maneira equilibrada, tanto as revistas das áreas de administração e contabilidade, como também as notas do Qualis Capes, evidenciando, com isso, a acuidade deste estilo de trabalho (a bibliometria) para o fomento, disseminação e divulgação de diversos assuntos inerentes à várias áreas do conhecimento, em especial, a administração e contabilidade realçadas nesta seção.

No geral, observou-se que 45 revistas publicaram de dois a 28 artigos sobre o tema ora analisado; oito periódicos publicaram apenas um artigo bibliométrico cada em 15 anos de estudos; e seis revistas não publicaram nenhum artigo sobre o assunto em investigação.

Este achado remete a Lei de Bradford (1934), que calcula a produtividade de revistas, estabelecendo, a posteriori, o núcleo de periódicos para o tema objeto de estudo. Sendo assim, o núcleo principal deste estudo é composto pelos periódicos: RAC, RAE, CGG, REPeC, CV\&V e ERC. Ou seja, estas revistas são particularmente as que se dedicam (BEUREN; SOUZA, 2008), de maneira mais assídua, à publicação sobre o tema bibliometria na literatura acadêmica nacional. Outros estudos realçam e compartilham os achados desta pesquisa, corroborando-os, são eles: Cardoso et al. (2005), Beuren e Souza (2008), Peleias et al. (2010), Peleias et al. (2013), Souza e Ribeiro (2013).

A Figura 2 expõe o padrão de crescimento dos estudos bibliométricos publicados de 1999 a 2013. 


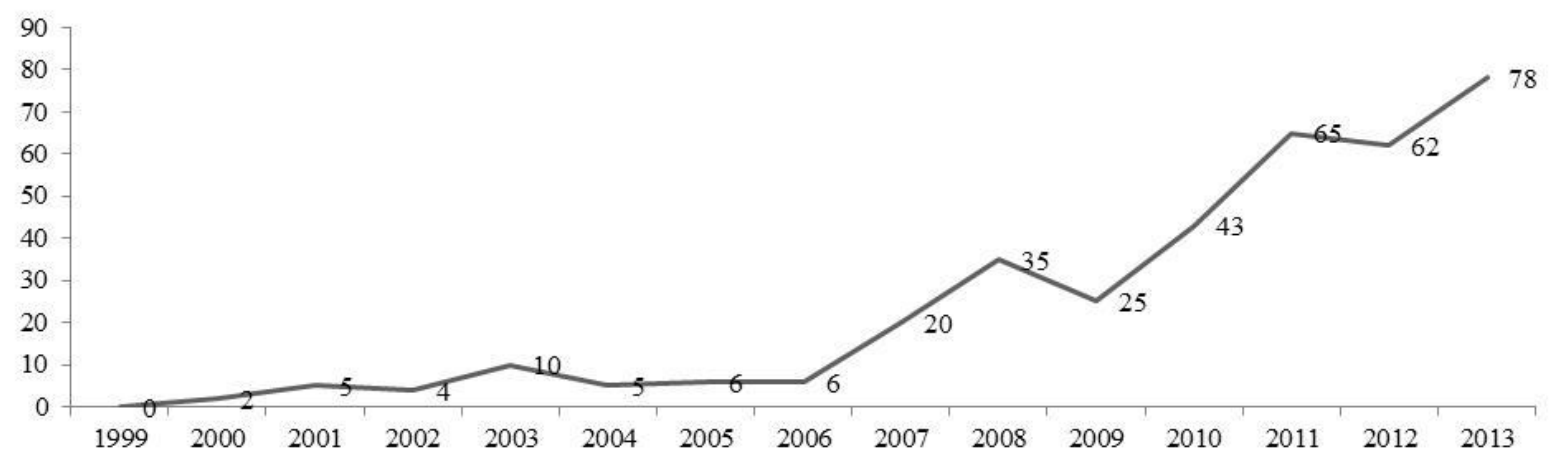

Figura 2: Padrão de crescimento das pesquisas bibliométricas Fonte: Dados da pesquisa

Verificando a Figura 2, observa-se que os estudos bibliométricos vêm crescendo de maneira exponencial nos últimos 15 anos, em especial, a partir do ano de 2007, tendo uma pequena queda no período de 2009, contudo, desde então, as publicações utilizando esta técnica de análise (bibliometria) vem crescendo, alcançando seu ápice de papers publicados em 2013. Neste panorama, realça-se que a evolução das publicações alcançou $3.800 \%$ desde o primeiro ano em que os artigos começaram a ser publicados (2000) até o período de 2013, que foi o mais produtivo entre os 15 anos investigados.

Esta informação ressalta a importância, maturidade e legitimidade da bibliometria nas áreas de Administração, Contabilidade e Turismo, pois, é inerente, se adequa, além de ser imprescindível para investigar, mapear, explorar e/ou analisar qualquer tema, seja ele, emergente e/ou embrionário na literatura acadêmica nacional. Entende-se, com isso, que os estudos bibliométricos são importantes para o processo de compreensão da estrutura intelectual científica, contribuindo para a construção e o fornecimento de resultados interpretativos e abrangentes para as áreas do conhecimento científico da literatura acadêmica nacional (CARDOSO et al., 2005).

A Figura 3 contempla as características de autoria dos 366 manuscritos identificados e analisados neste estudo.

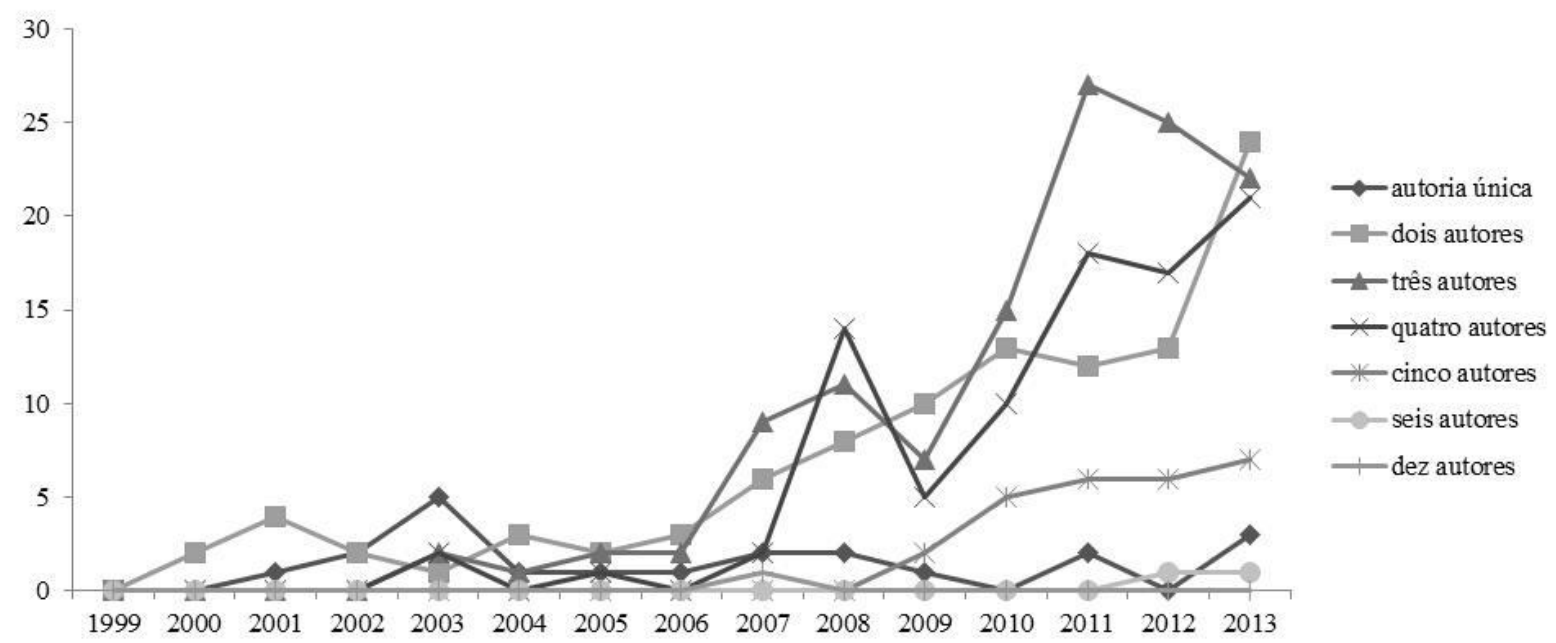

Figura 3: Características de autoria

Fonte: Dados da pesquisa

Observando a Figura 3, nota-se a predominância de artigos publicados em parceria $(94,26 \%)$, sobretudo, com três, dois e quatro autores, ou seja, 33,61\%, 28,14\% e 24,59\% do montante de 366 papers, respectivamente. Tal resultado pode indicar grupos de pesquisa consolidados que trabalham a bibliometria para construir, difundir, socializar e divulgar o conhecimento cientifico (LEITE FILHO, 2008), mediante uma miscelânea de temas que se manifestam em decorrência da flexibilidade e da abrangência que a análise bibliométrica proporciona para os diversos campos do conhecimento acadêmico (MASCARENHAS; BARBOSA, 2013). 
A Figura 4 evidencia os 772 autores identificados neste estudo, com ênfase aos 11 pesquisadores mais profícuos.

Ao analisar a Figura 4, constata-se que Sandra Rolim Ensslin foi a autora mais produtiva, no que tange a estudos sobre bibliometria, com 17 artigos publicados em 15 anos de pesquisa. Em seguida, destaca-se 0 pesquisador Luciano Rossoni, com 14 publicações; e logo após o autor Henrique César Melo Ribeiro, com 11 manuscritos publicados. Diante disso, versa-se a pesquisa do autor Urbizagastegui (2016), o qual também coloca em evidencia os três acadêmicos realçados nesta seção do estudo.

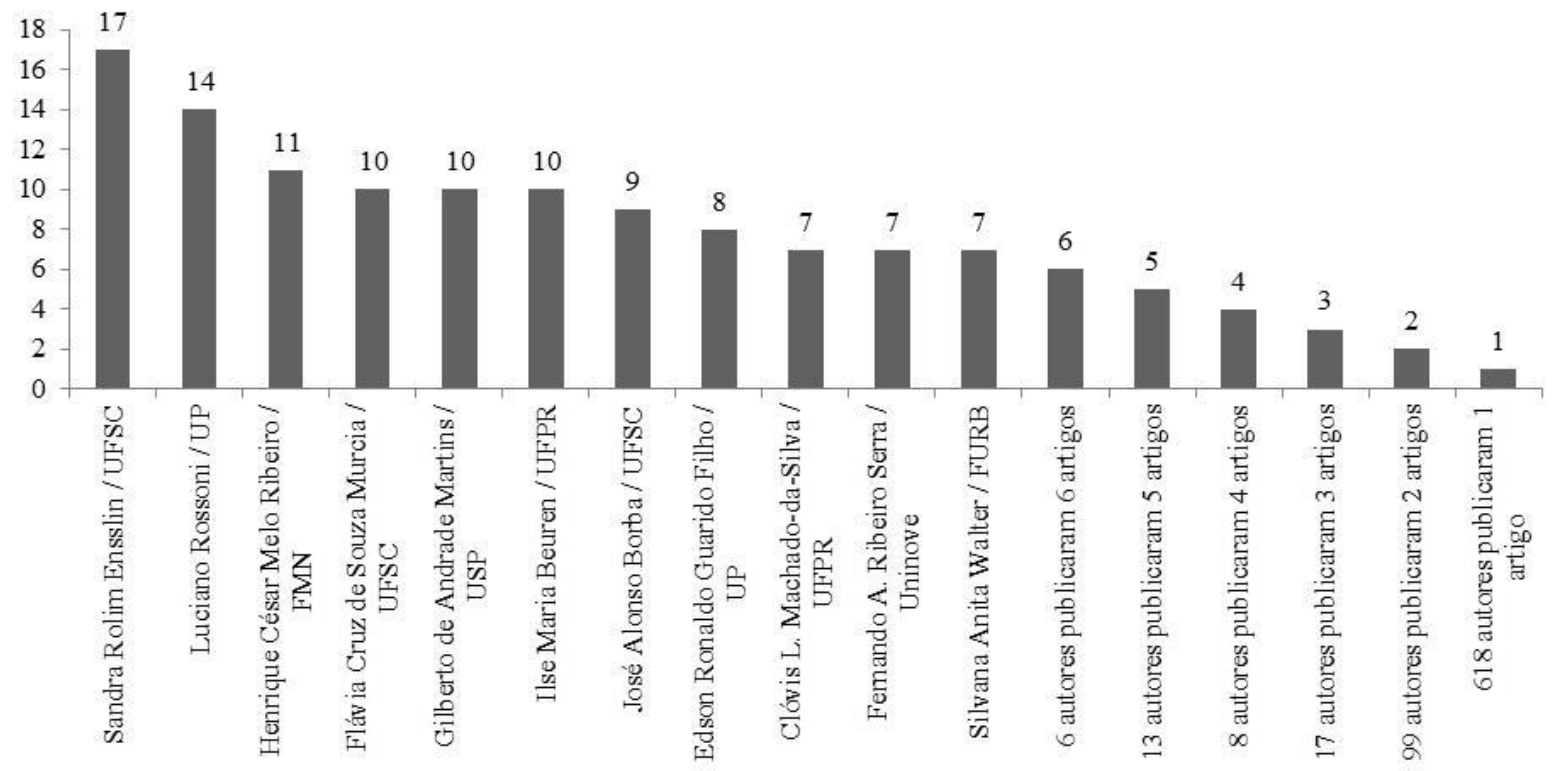

Figura 4: Autores

Fonte: Dados da pesquisa

Realçam-se também os autores: Flávia Cruz de Souza Murcia, Gilberto de Andrade Martins e llse Maria Beuren, todos com 10 publicações sobre o tema. Com nove, aparece José Alonso Borba; e logo depois, com oito, o articulista Edson Ronaldo Guarido Filho. Com sete aparecem os pesquisadores: Clóvis L. Machado-da-Silva, Fernando A. Ribeiro Serra e Silvana Anita Walter. É interessante notar que dos 11 autores que se destacaram nesta seção, oito são de IESs localizadas na região Sul (UFSC, UP, UFPR e FURB); dois pesquisadores são de IESs localizadas no Sudeste (USP e Uninove) e um autor tem vinculo com uma IES da região Nordeste (FMN).

No contexto geral, dos 772 autores identificados nesta pesquisa, 154 (19,95\%), publicaram de dois a 17 artigos; e a grande maioria, ou seja, 618 (80,05\%), publicou apenas um artigo cada. Tal resultado remete, de maneira comparável, a Lei de Lotka que realça que poucos pesquisadores publicam muito e muitos autores publicam pouco (SOUZA; RIBEIRO, 2013), colocando assim em evidência a produtividade dos autores (MENDONÇA NETO; RICCIO; SAKATA, 2009), enfatizando como os autores, em especial os mais profícuos, contribuem para o aperfeiçoamento da ciência (VANTI, 2002).

Alguns estudos bibliométricos corroboram, de maneira similar, com os achados da Figura 4, são eles: Cardoso et al. (2005), Riccio, Mendonça Neto e Sakata (2007), Beuren e Souza (2008), Moretti e Campanario (2009), Rossoni e Hocayen-da-Silva (2009), Matos et al. (2012) e Souza e Ribeiro (2013). Estes estudos enfatizam a importância e a relevância de se relacionar a Lei de Lotka com a produtividade dos pesquisadores.

A Figura 5 visualiza a rede de coautoria dos 772 pesquisadores identificados neste trabalho, com 772 nós e 2405 laços. 


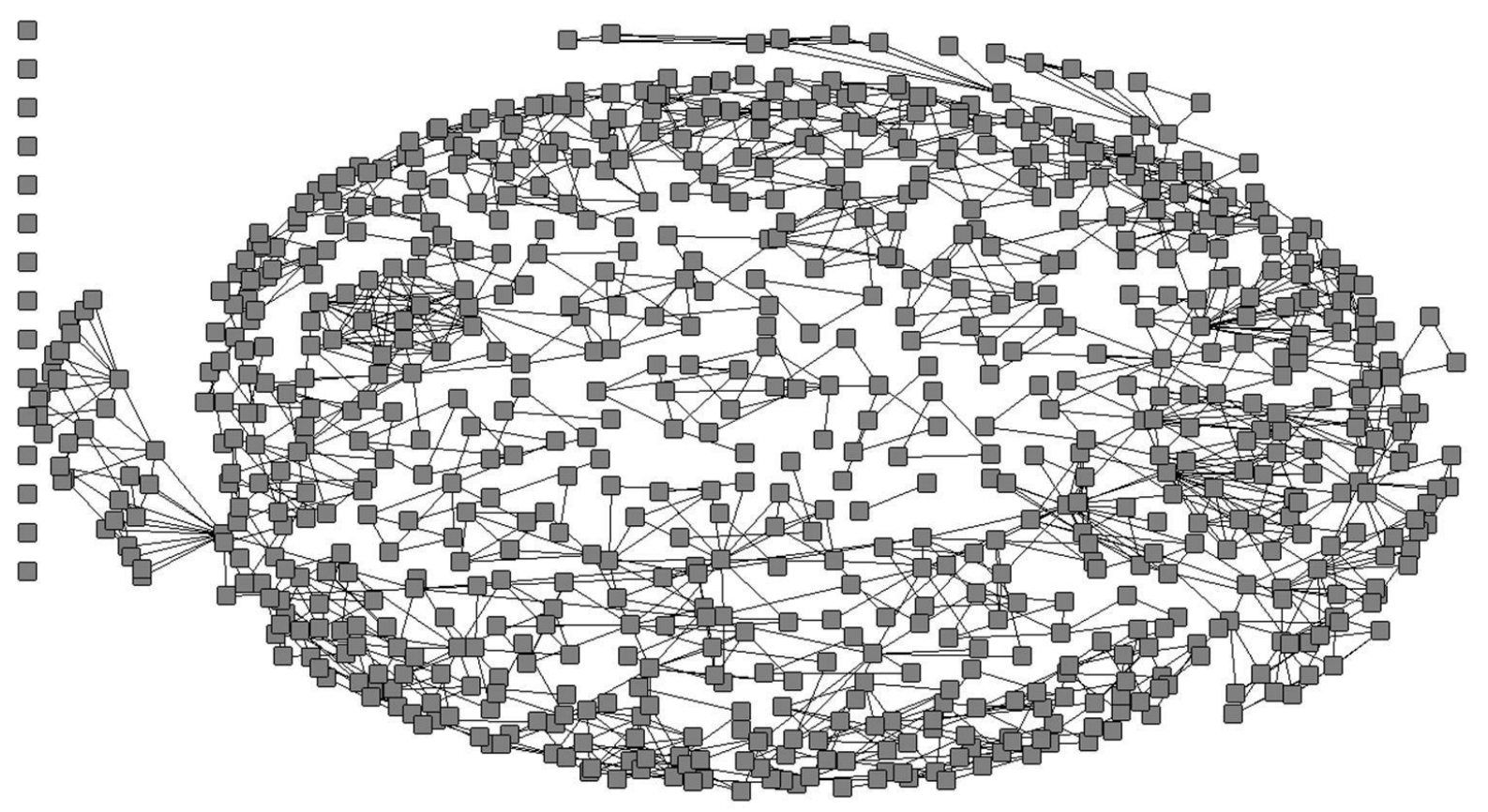

Fonte: Dados da pesquisa

Analisando a Figura 5, contempla-se que somente 15 autores publicaram sem parceria, e a grande maioria, isto é, 757 (98,06\%), publicou em conjunto com no mínimo um autor como parceiro. Esta informação remete aos dados enfatizados na Figura 3 deste estudo, que evidencia também a predominância de publicações em parceria. Contudo, analisando a densidade da referida rede social, verifica-se o valor de 0.0045 , ou seja, 0,45\% das interações são realizadas.

A Figura 6 realça a mesma rede de coautoria enfatizada na Figura 5, contudo, elencando os autores com maior centralidade de grau.

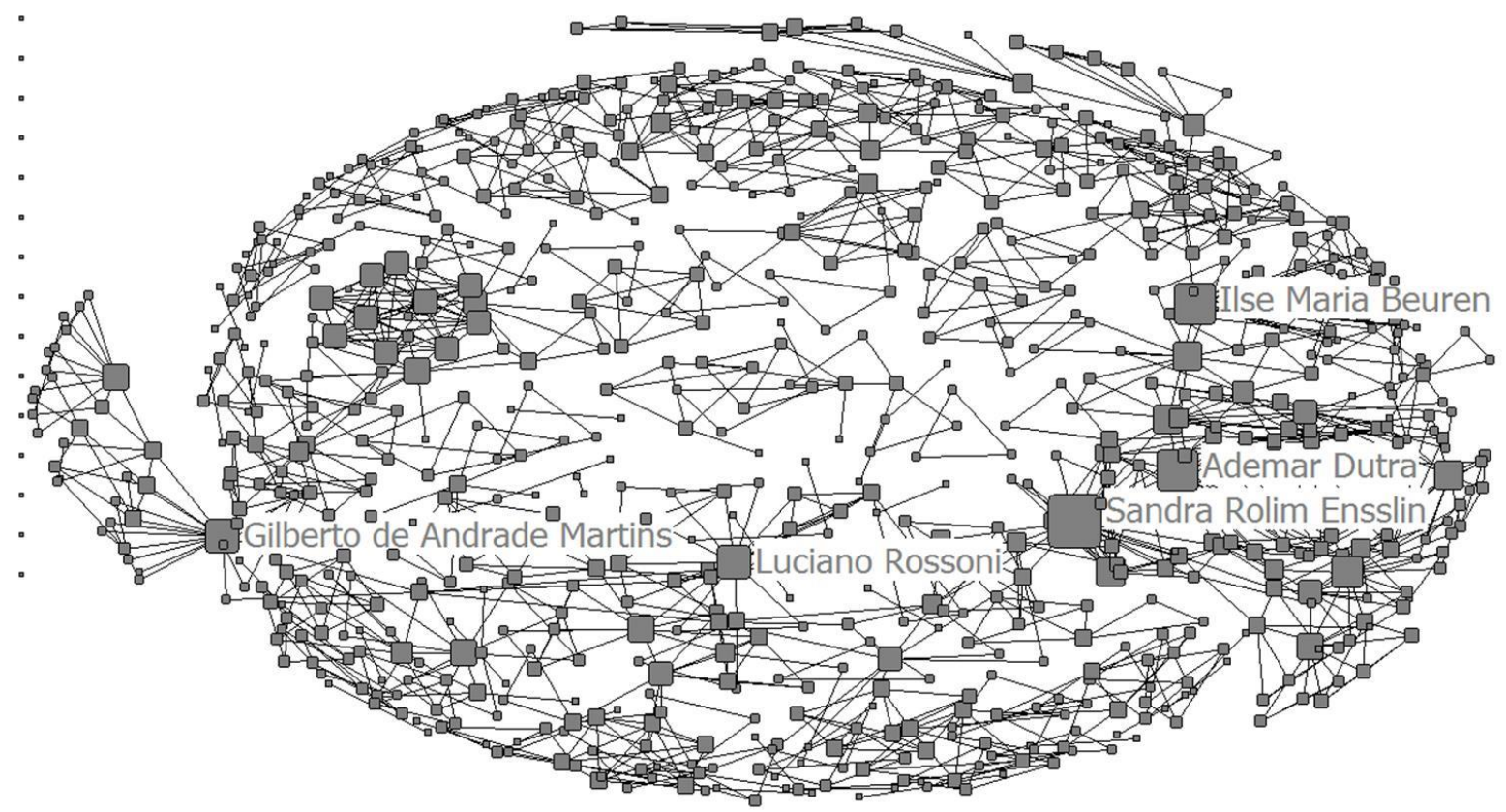

Figura 6: Redes de coautoria (degree)

Fonte: Dados da pesquisa 
Entende-se, com isso, que estes quatro autores realçados se beneficiam de sua colaboração com outros autores para conseguir uma maior produtividade. Sendo assim, compreende-se que aqueles autores com maior centralidade de grau apresentam maior probabilidade de possuírem maior produção de papers (MENDES-DASILVA; ONUSIC; GIGLIO, 2013).

Os estudos bibliométricos: Francisco (2011), Nascimento e Beuren (2011), Mendes-da-Silva, Onusic e Giglio (2013) corroboram, de maneira análoga, com os achados desta seção, pois, destacam, em suas respectivas pesquisas, a alta centralidade de grau dos pesquisadores.

A Figura 7 evidencia as 153 IESs identificadas nesta pesquisa, que enfatiza as 18 IESs com maior produção acadêmica sobre o tema em análise.

Verificando a Figura 7, realça-se a produção de artigos da USP, com 53 publicações e, logo em seguida, ressalta-se a UFSC, com 50 papers publicados, sendo, consideradas portanto as IESs com maior destaque no que se refere a publicação de artigos bibliométricos.

É interessante notar que a USP só se faz representar entre os 11 autores mais profícuos deste estudo por Gilberto de Andrade Martins, as demais publicações da USP estão pulverizadas em um número maior de pesquisadores, em comparação com a UFSC, pois esta é representada por três autores entre os 11 mais produtivos, são eles: Sandra Rolim Ensslin, Flávia Cruz de Souza Murcia e José Alonso Borba, concentrando assim seus artigos nestes autores.

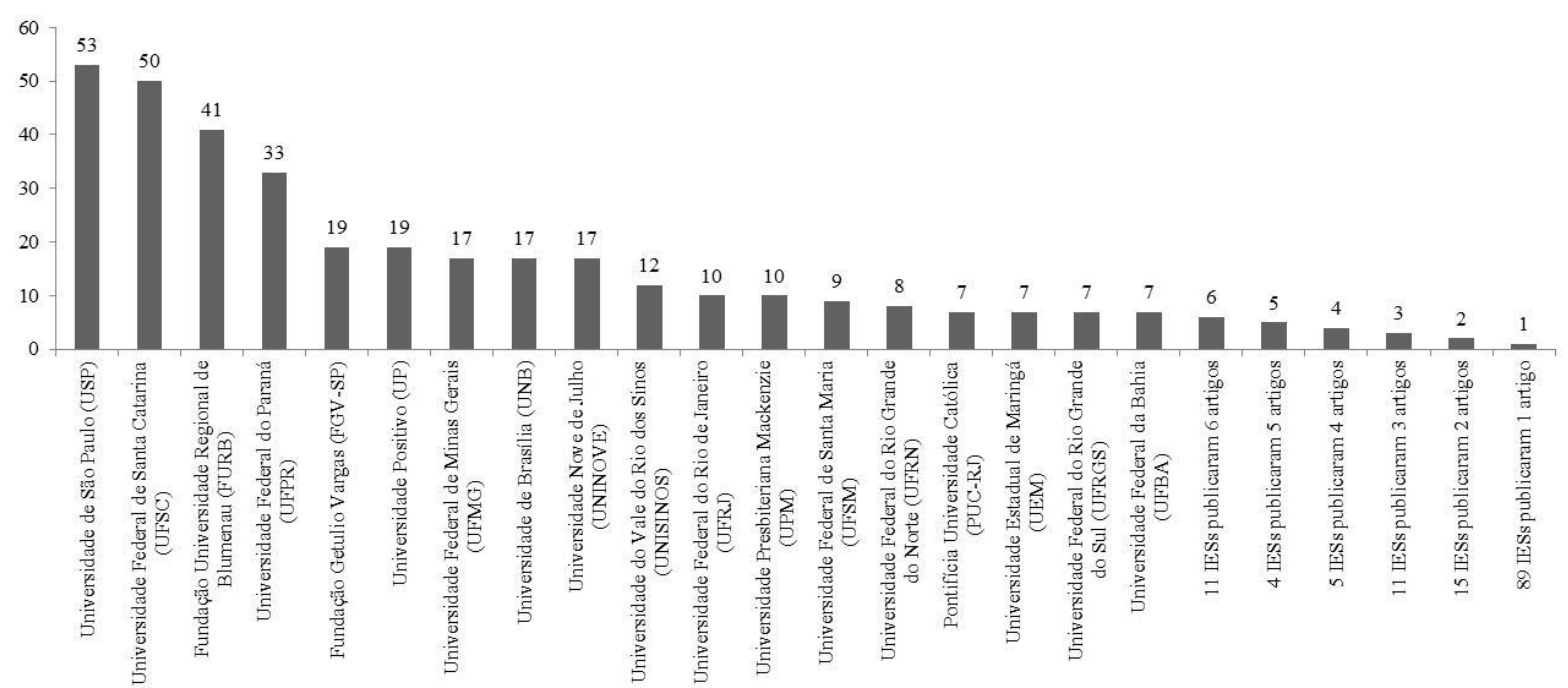

Figura 7: IESs

Fonte: Dados da pesquisa

As demais IESs que se destacaram nesta seção, foram: FURB, UFPR, com 41 e 33 artigos publicados. Com 19 aparecem as IESs: FGV-SP e UP. Com 17 artigos publicados realçam-se as IESs: UFMG, UNB e UNINOVE. Com 10 publicações, as IESs: UFRJ e UPM.

Em um panorama geral, das 153 IESs analisadas neste estudo, 64 (41,83\%) publicaram mais de dois artigos; e 89 (58,17\%), apenas um artigo. Observando esta informação, verifica-se certa predominância de IESs que publicam apenas uma vez sobre o tema em investigação, contudo, é interessante notar a quantidade de instituições que publicaram mais de uma vez, mostrando com isso a maturidade e importância da bibliometria para o fomento da colaboração entre as IESs. Esta informação é confirmada na Figura 8, que evidencia a rede social destas IESs.

A Figura 8 contempla a rede social das 153 IESs deste estudo, com 153 nós e 478 laços.

Primeira informação que remete ao visualizar a Figura 8, é o grande grupo de IESs que se conectam, direta ou indiretamente, na rede social, ou seja, 129 (84,31\% do montante) IESs fazem esta grande rede de colaboração, enfatizada no centro da Figura 8. Esta afirmativa é apoiada pela Figura 7 em termos de parceria em publicação. 
Contudo, a densidade da rede das IESs foi mensurada em 0.0252 , isto é, 2,52\% das interações são realizadas. Tal dado é similar a densidade da rede de coautoria (Figura 5). Isto pode representar que, mesmo a bibliometria sendo uma técnica de análise aplicada para melhor conhecer qualquer tema na área de Administração, Contabilidade e Turismo, a rede social dos autores e das IESs, no que tange as interações, está muito abaixo do que é sensato ter. Em contrapartida, é visível e tangível o crescimento deste tipo de estudo, podendo ser fator imprescindível para o aumento das parcerias e, porventura, das conexões entre os atores deste estudo.

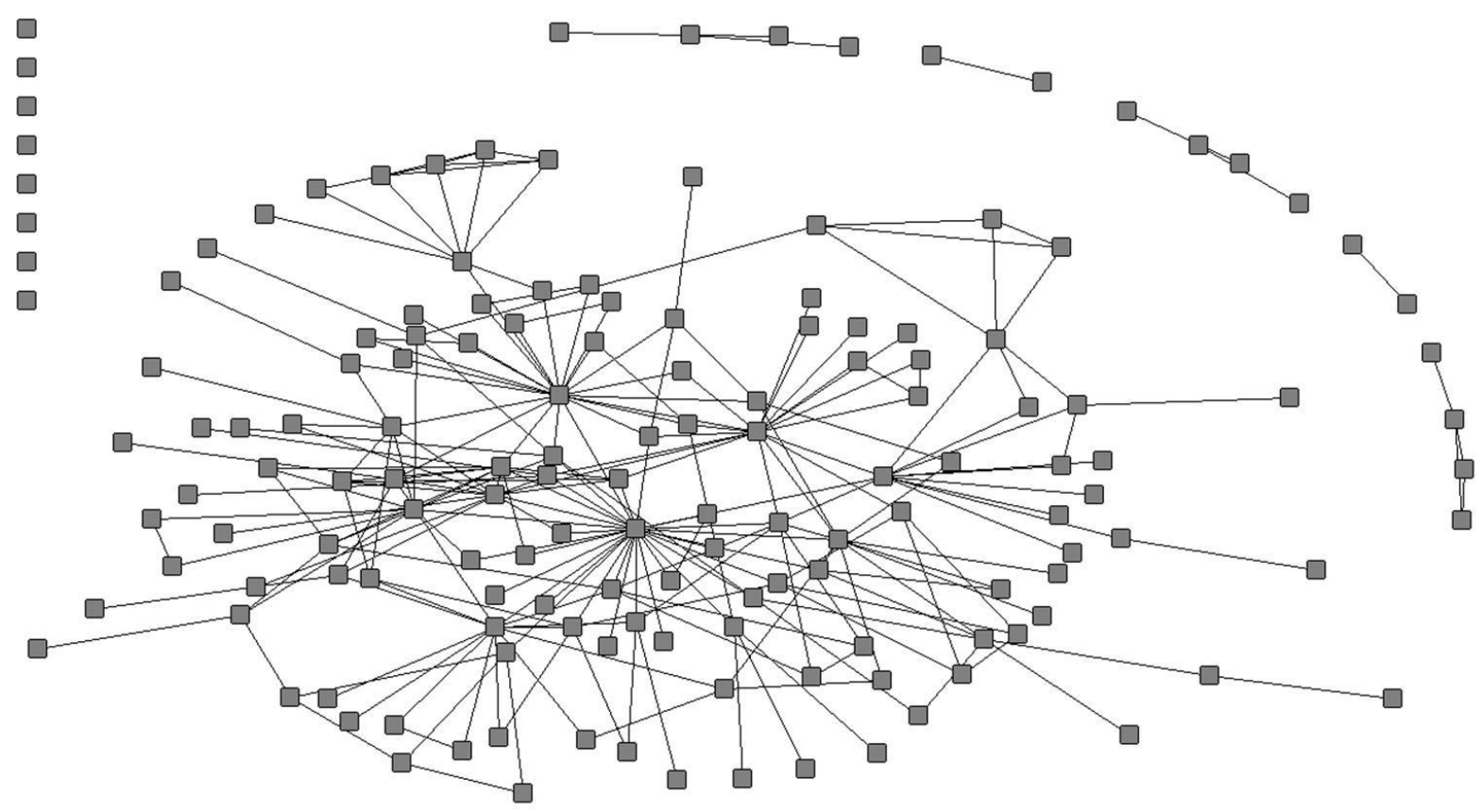

Figura 8: Redes das IESs

Fonte: Dados da pesquisa

Já a Figura 9 é parecida com a Figura 8, entretanto, ela enfatiza os atores (IESs) com maior centralidade de grau desta rede.

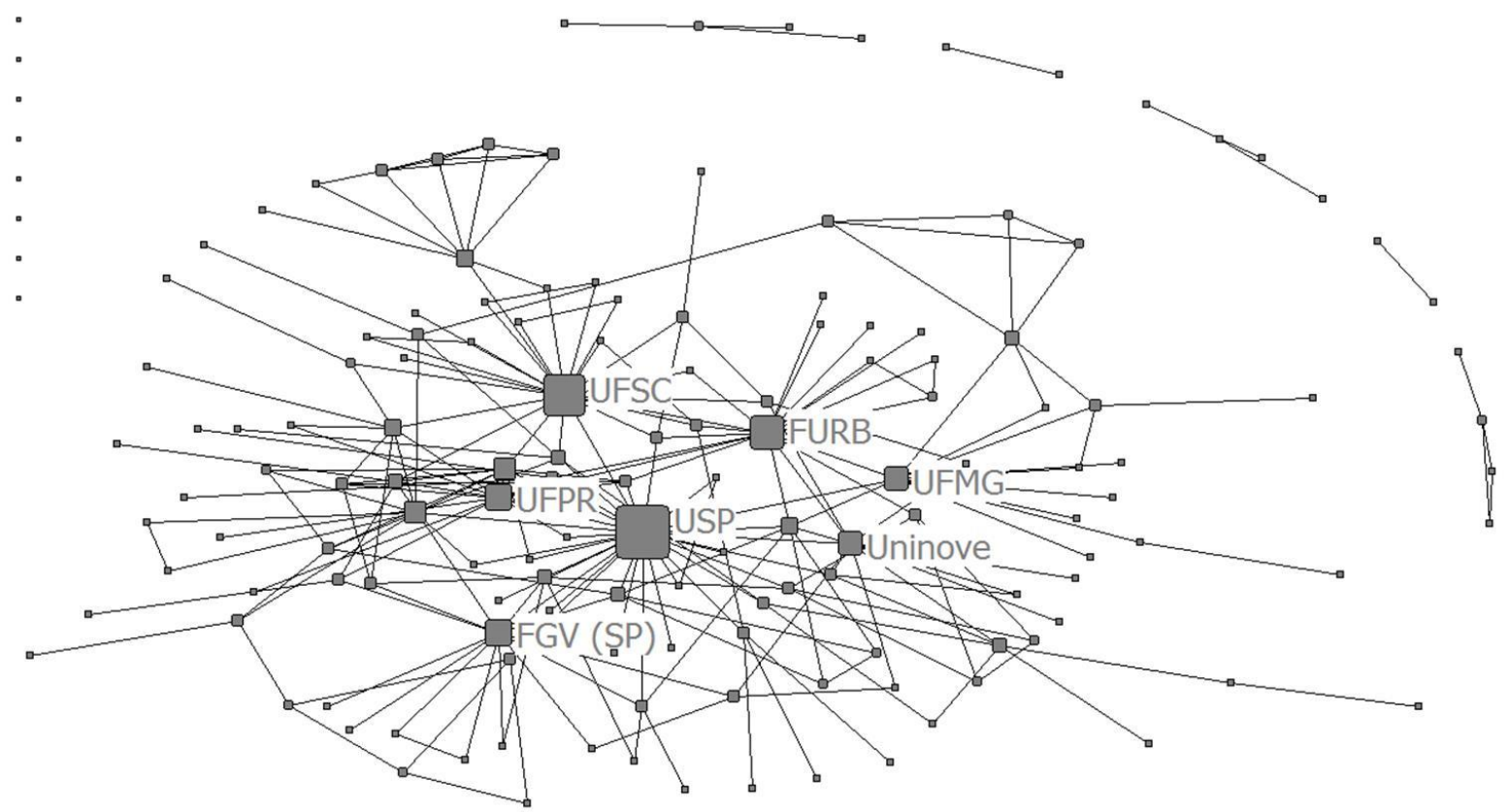

Figura 9: Redes das IESs (Degree)

Fonte: Dados da pesquisa 
Analisando a Figura 9, evidenciam-se as IESs: USP, UFSC, FURB, FGV (SP), UFPR, UFMG e Uninove como as mais centrais deste estudo, e, além disso, estão entre as 10 mais produtivas deste estudo. Tal informação mostra que a quantidade de conexões impacta diretamente na produção de artigos sobre o tema em análise. Tal afirmação é legitimada nos estudos de: Francisco (2011) e Ribeiro e Costa (2013), que contemplam que as IESs mais produtivas também se destacam como as mais centrais.

A Figura 10 realça a rede social dos 19 estados e dos sete países envolvidos neste estudo.

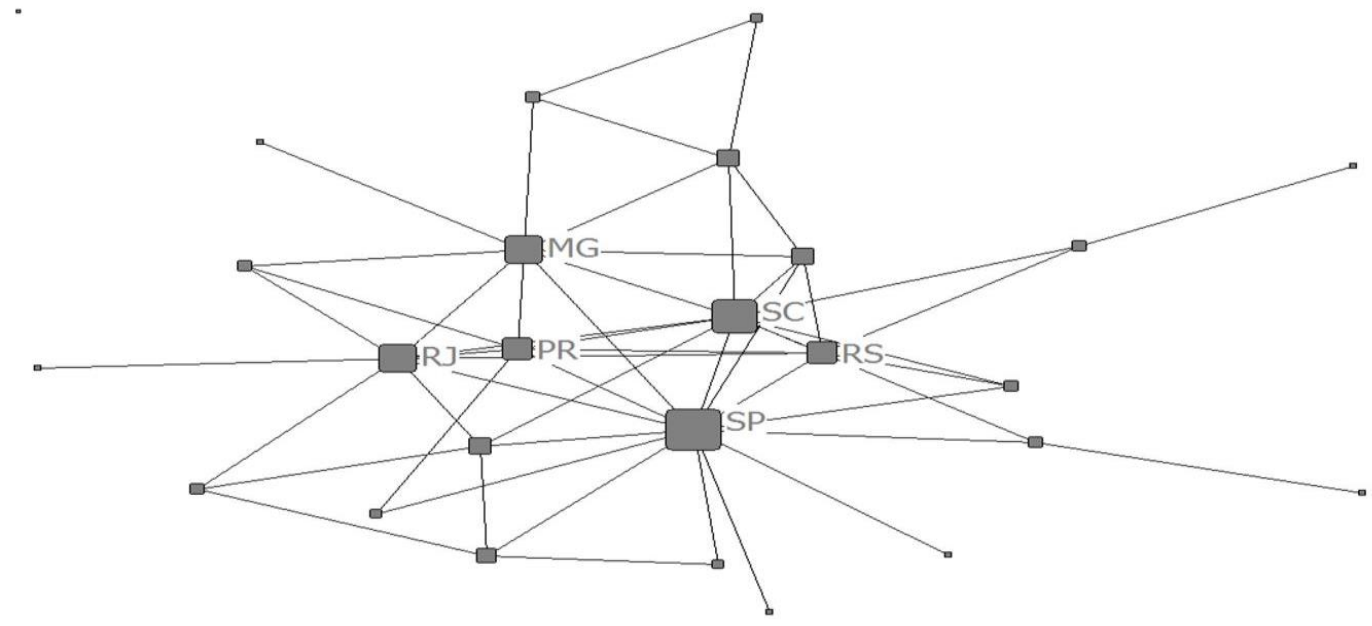

Figura 10: Redes dos estados e países (Degree)

Fonte: Dados da pesquisa

Observando a Figura 10 enfatizam-se os estados mais centrais deste estudo. Ressalta-se que estes estados se conectam com as IESs desta pesquisa. Sendo assim, destacam-se SP, SC, MG, PR, RS e RJ como os estados com maior centralidade de grau. Entre estes seis estados enfatizados, os quatro primeiros se fazem representar pelas IESs mais produtivas e centrais (Figuras 7 e 9 respectivamente), ou seja, USP, UFSC, FURB, UFPR e UFMG.

A Figura 11 visualiza a nuvem de palavras-chave (Francisco, 2011) identificada nos 366 artigos analisados nesta pesquisa.

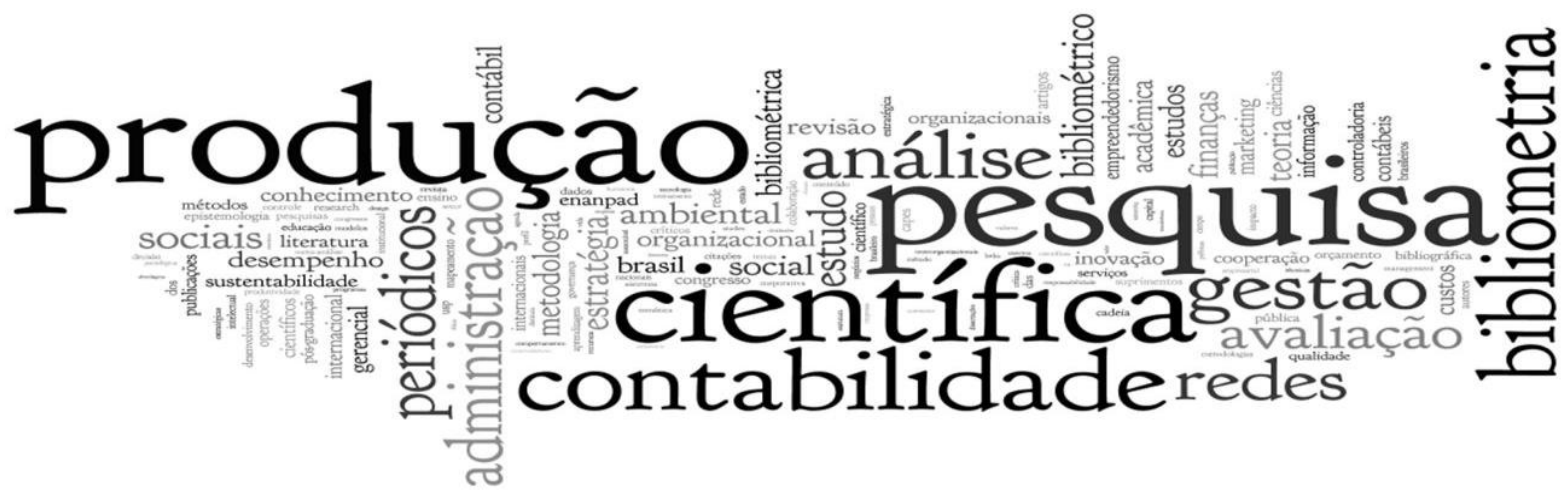

Figura 11: Palavras-chave

Fonte: Dados da pesquisa

Analisando a nuvem de palavras-chave da Figura 11, colocam-se em evidência as palavras: produção, pesquisa, científica, contabilidade, bibliometria, análise, gestão, redes, periódicos, administração, entre outras. Estas palavras enfatizadas na Figura 11 vão ao encontro do objetivo deste estudo, que foi investigar as publicações bibliométricas. Destacam-se também as áreas de contabilidade e administração. Remete assim a 
Lei de Zipf que calcula a frequência do aparecimento das palavras em textos, criando uma lista de possíveis temas mais abordados (VANTI, 2002)

É interessante notar também que a palavra: periódicos realça-se, neste contexto. Além disso, salienta-se que as revistas foram foco principal de muitas publicações bibliométricas trabalhadas nestes 15 anos, com relevo para as revistas: Revista Contabilidade \& Finanças (USP), Revista Contemporânea de Contabilidade (UFSC), em especial para a primeira, que aparece com proeminência em quatro estudos.

É importante ressaltar também a importância dos congressos, que foram fontes especiais de dados, gerando informações específicas para entendimento de vários temas, entre estes encontros da área de administração e contabilidade, ressalvam-se: Associação Nacional de Pós-Graduação e Pesquisa em Administração, Congresso USP de Controladoria e Contabilidade, Congresso Brasileiro de Custos, Associação Nacional dos Programas de Pós-Graduação em Ciências Contábeis.

A Figura 12 aborda 167 temas identificados em 366 artigos analisados nesta pesquisa, com especial atenção para os primeiros 20 temas.

Analisando a Figura 12, enfatiza-se o assunto ensino e pesquisa em contabilidade, aparecendo como tema central em 38 publicações. Assuntos que focam a temática metodologia científica vieram logo após, com 18 artigos. O tema ensino e pesquisa em administração aparece como o terceiro mais publicado, com 13 artigos, junto com o assunto estratégia. Com 10 publicações vem o tema contabilidade. Com oito papers realçam-se os temas contabilidade gerencial e empreendedorismo. Com sete enfatizam-se os assuntos: controladoria, gestão de custos, gestão de pessoas, e marketing.

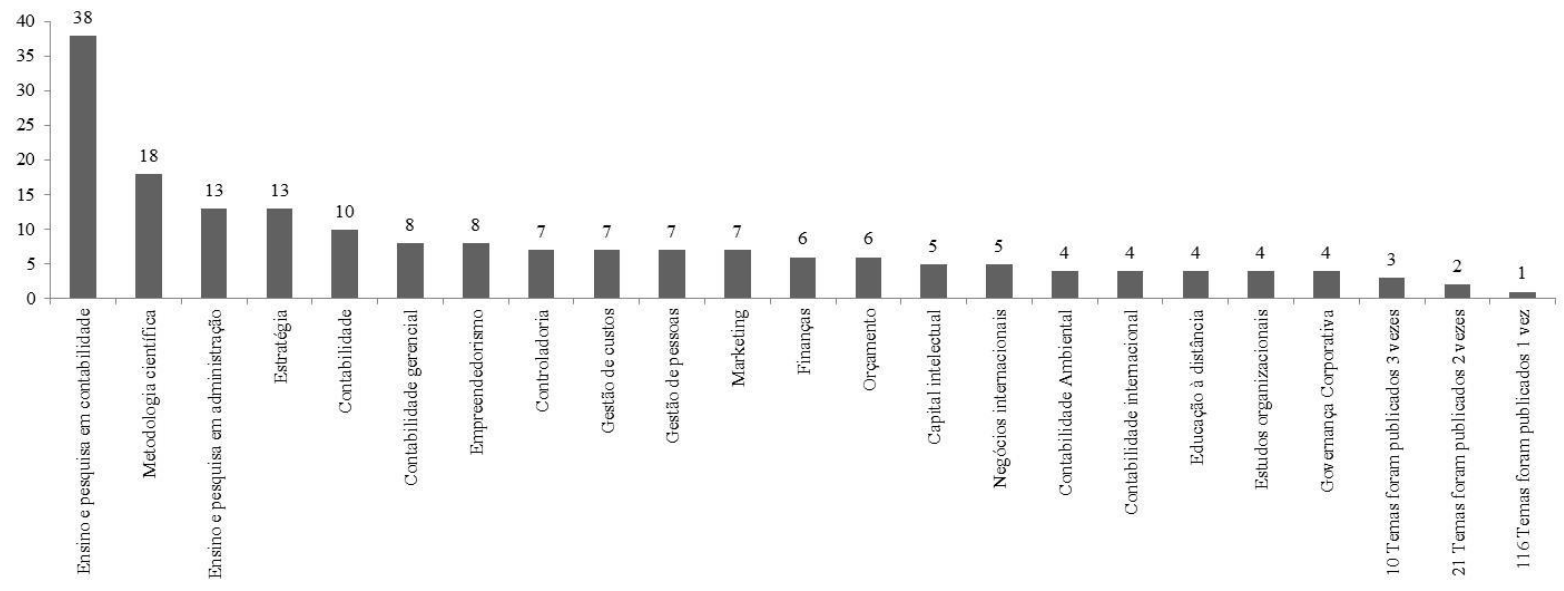

Figura 12: Temas

Fonte: Dados da pesquisa

Bem, observando estes 11 primeiros temas mais vistos como assuntos principais neste estudo, constata-se que 10 relacionam-se diretamente com as áreas de administração e contabilidade, ou seja, cinco temas para cada área, o que de alguma forma, vai ao encontro do que foi ressaltado na Figura 11. É interessante notar que este equilíbrio entre as áreas de administração e contabilidade é visto também quando se focam os periódicos, pois, sete são da área contábil e seis, da área de administração.

É salutar informar que, entre os três temas mais publicados, dois realçam o ensino e a pesquisa na contabilidade e/ou na administração. Diante desse fato, é preponderante enfatizar que estas pesquisas se fundamentaram nos bancos de dados, em especial dos artigos publicados em anais com foco na: Associação Nacional de Pós-Graduação e Pesquisa em Administração, Congresso USP de Controladoria e Contabilidade, Congresso Brasileiro de Custos, Associação Nacional dos Programas de Pós-Graduação em Ciências Contábeis. 


\section{Considerações finais}

O objetivo desta pesquisa foi analisar o perfil e o padrão de crescimento da produção acadêmica dos artigos bibliométricos, nos periódicos nacionais da área de Administração, Contabilidade e Turismo (Triênio 2010-2012), durante o período de 1999 a 2013. Para isso, foram utilizadas as técnicas de análise bibliométrica e de rede social para mensurar as variáveis: periódicos e os de maior destaque, evolução das pesquisas sobre bibliometria, características de autoria, autores, redes de coautoria, redes de coautoria (degree), IESs, rede das IESs, rede das IESs (degree), redes dos estados e países (degree), palavras-chave; e temas.

Observou-se que a RAC e a RAE foram os periódicos que mais publicaram estudos bibliométricos. Sendo que estes estudos, no contexto das 53 revistas que publicaram ao menos um artigo, começaram a crescer em 2007, alcançando seu pico em 2013. Entre estas publicações, ressaltam-se as realizadas em parceria, com, no mínimo dois autores. No que tange aos autores, a pesquisadora Sandra Rolim Ensslin foi a mais profícua, com 17 artigos publicados, além disso, ela se sobressai como autora mais central da rede de coautoria que se encontra com baixa densidade. Em relação as IESs, a USP, seguida de perto da UFSC, são as mais produtivas no contexto de artigos publicados sobre bibliometria, sendo que aparecem e são realçadas também como as IESs mais centrais desta pesquisa.

Em relação aos temas mais abordados, evidenciam-se os temas: ensino e pesquisa em contabilidade, metodologia científica, ensino e pesquisa em administração, estratégia, contabilidade, contabilidade gerencial, empreendedorismo, controladoria, gestão de custos, gestão de pessoas e marketing. Estes temas em destaque realçam o equilíbrio existente entre as áreas de administração e contabilidade.

Em suma, dos 167 temas identificados nesta pesquisa, 51 foram publicados de duas a 38 vezes e a grande maioria, ou seja, 116, foi publicado apenas uma vez. Esta informação mostra como a pesquisa bibliométrica é horizontal, pois se torna uma ferramenta poderosa para melhor compreender uma miscelânea de assuntos, contribuindo para o fomento, aperfeiçoamento, socialização e evidenciação do conhecimento científico das áreas de administração e contabilidade em especial.

Este estudo também contribuiu para melhor entender e compreender como estão os padrões de produção acadêmica dos artigos bibliométricos em 15 anos de estudos. Outra contribuição é observar e constatar que os estudos bibliométricos deixaram de ser emergentes e se tornaram fontes valiosas de estudos, pois, por meio das técnicas de análise bibliométricas, os autores conseguem estudar diversos temas (como visto neste trabalho), proporcionando, com isso, uma visão ampla de temáticas ainda pouco vistas no contexto literal acadêmico nacional ou até mesmo no âmbito acadêmico internacional. Neste contexto, estes temas podem ser melhor estudados, fazendo com que eles possam sair da fase embrionária que se encontram, para tornarem-se emergentes algum dia.

Portanto, conclui-se, de maneira macro, o perfil e o padrão de crescimento dos estudos acadêmicos em bibliometria, para propiciar com isso uma melhor compreensão da importância deste estilo de estudo para a literatura acadêmica nacional. Esse entendimento, por sua vez, influenciará também na construção e no aperfeiçoamento da estrutura do conhecimento científico para as áreas de administração e contabilidade.

A principal limitação deste estudo foi analisar apenas os estudos dos periódicos da Área de Administração, Contabilidade e Turismo da Qualis Capes (2014). Neste contexto, sugere-se ampliar esta análise incorporando outras áreas do conhecimento, como, por exemplo, da Ciência da Informação, que congrega muitos estudos bibliométricos, pois foi a área que iniciou tais pesquisas no Brasil. Sugere-se também, para futuros estudos, expandir a análise dos 167 temas identificados nesta pesquisa, mediante, uma análise de seu conteúdo. Outra sugestão é aperfeiçoar as técnicas de análise bibliométrica e de rede social, por meio de estatísticas multivariadas de dados, além de expandir a análise de redes enfatizando as centralidades de intermediação e de aproximação. 


\section{Referências}

ACEDO, F. J.; BARROSO, C.; GALAN, J. L. The resource-based theory: dissemination and main trends. Strategic Management Journal, v. 27, n. 7, p. 621-636, 2006.

BEUREN, I. M.; PINTO, J.; ZONATTO, V. C. da S. Abordagens da Controladoria nos Trabalhos do Congresso USP de Controladoria e Contabilidade: um enfoque nas perspectivas conceitual, procedimental e organizacional. Revista Contemporânea de Contabilidade, v. 9, 17, p. 3-16, 2012.

BEUREN, I. M.; SCHLINDWEIN, A. C.; PASQUAL, D. L. Abordagem da controladoria em trabalhos publicados no Enanpad e no Congresso USP de controladoria e contabilidade de 2001 a 2006 . Revista Contabilidade \& Finanças, v. 18, n. 45, p. 2237,2007

BEUREN, I. M.; SOUZA, J. C. Em busca de um delineamento de proposta para classificação dos periódicos internacionais de contabilidade para o Qualis Capes. Revista Contabilidade \& Finanças, v. 19, n. 46, p. 44-58, 2008.

BEYDA, T. T.; MACEDO-SOARES, T. D. L. van A. de. Identidade organizacional: análise crítica da produção acadêmica brasileira de 2004 a 2009. Revista de Administração da USP, v. 45, n. 4, p. 400-414, 2010.

BORBA, M. L. de; HOELTGEBAUM, M.; SILVEIRA, A. A produção científica em empreendedorismo: análise do Academy of Management Meeting: 1954-2005. Revista de Administração Mackenzie, v. 12, n. 2, p. 169-206, 2011.

BRADFORD, S.C. Sources of information on specific subjects. Engineering: An Illustrated Weekly, p. 85-86, 1934.

BRANDÃO, S. M.; BRUNO-FARIA, M. de F. Inovação no setor público: análise da produção científica em periódicos nacionais e internacionais da área de administração. Revista de Administração Pública, v. 47, n. 1, p. 227-248, 2013.

BRUNELLI, M. DE Q.; MACEDO-SOARES, T. D. L. van A. de; ZOUAIN, D. M.; BORGES, A. P. Scientific research in tourism: review of the literature from 2005 to 2009. Revista de Administração Pública, v. 44, n. 5, p. 1225-1240, 2010.

CALDAS, M. P.; TINOCO, T. Pesquisa em gestão de recursos humanos nos anos 1990: um estudo bibliométrico. Revista de Administração de Empresas, v. 44, n. 3, p. 100-114, 2004

CARDOSO, R. L.; MENDONÇA NETO, O. R. de; RICCIO, E. L.; SAKATA, M. C. G. Pesquisa científica em contabilidade entre 1990 e 2003. Revista de Administração de Empresas, v. 45, n. 2, p. 34-45, 2005.

CARDOSO, R. L.; PEREIRA, C. A.; GUERREIRO, R. Perfil das pesquisas em contabilidade de custos apresentadas no EnANPAD no período de 1998 a 2003. Revista de Administração Contemporânea, v. 11, n. 3, p. 177-198, 2007.

DAVEL, E.; ALCADIPANI, R. Estudos críticos em administração: a produção científica brasileira nos anos 1990. Revista de Administração de Empresas, v. 43, n. 4, p. 72-85, 2003

DURISIN, B.; PUZONE, F. Maturation of corporate governance research, 1993-2007: an assessment. Corporate Governance: An International Review, v. 17, n. 3, p. 266-291, 2009.

ENSSLIN, L.; ENSSLIN, S. R.; PINTO, H. de M. Processo de investigação e análise bibliométrica: avaliação da qualidade dos serviços bancários. Revista de Administração Contemporânea, v. 17, n. 3, p. 325-349, 2013.

FARIA, M.; FIGUEIREDO, K. F. Casos de ensino no Brasil: análise bibliométrica e orientações para autores. Revista de Administração Contemporânea, v. 17, n. 2, p. 176-197, 2013.

FERREIRA, M. P. A bibliometric study on ghoshal's managing across borders. The Multinational Business Review, v. 19, $\mathrm{n}$. 4, p. 357-375, 2011.

FRANCISCO, E. de R. RAE-eletrônica: exploração do acervo à luz da bibliometria, geoanálise e redes sociais. Revista de Administração de Empresas, v. 51, n. 3, p. 280-306, 2011.

GOMES, E. do C. O.; SCARPIN, J. E. Estudo bibliométrico acerca das transferências intergovernamentais publicadas no período de 2001 a 2008. Revista de Administração e Contabilidade da Unisinos, v. 9, n. 2, p. $189-203,2012$.

GRAEML, A. R.; MACADAR, M. A. Análise de citações utilizadas em ADI: 10 anos de anais digitais do Enanpad (1997-2006). Revista de Administração Contemporânea, v. 14, n. 1, p. 122-148, 2010.

GUARIDO FILHO, E. R.; MACHADO-DA-SILVA, C. L.; ROSSONI, L. The social and intellectual dimensions in the construction of scientific knowledge: the institutional theory in organization studies in Brazil. Brazilian Administration Review, v. 7, n. 2, p. 136-154, 2010

HARRIS, J. E. A review of Latin American corporate governance literature: 2000-2009. Corporate Governance, v. 9, n. 5, p. $635-648,2009$.

HART, S. L.; DOWELL, G. A natural-resource-based view of the firm: fifteen years after. Journal of Management, v. 37 , n. 5 , p. 1464-1479, 2011. 
JABBOUR, C. J. C.; SANTOS, F. C. A.; BARBIERI, J. C. Gestão ambiental empresarial: um levantamento da produção científica brasileira divulgada em periódicos da área de administração entre 1996 e 2005. Revista de Administração Contemporânea, v. 12, n. 3, p. 689-715, 2008.

KNEIPP, J. M.; ROSA, L. A. B. da; BICHUETI, R. S.; POZZER, R. H. P.; SCHUCH JÚNIOR, V. F. Análise bibliométrica da produção científica da Revista de Administração da UFSM: em busca de novas perspectivas e desafios. Revista de Administração da UFSM, v. 6, n. 2, p. 443-458, 2013

LOTKA, A.J. The frequency distribution of scientific productivity. Journal of the Washington Academy of Science, v. 16, p. 317-23, 1926

LEAL, R. P. C.; ALMEIDA, V. de S. E.; BORTOLON, P. M. Produção científica brasileira em finanças no período 2000-2010. Revista de Administração de Empresas, v. 53, n. 1, p. 46-55, 2013.

LEITE FILHO, G. A. Padrões de produtividade de autores em periódicos e congressos na área de contabilidade no Brasil: um estudo bibliométrico. Revista de Administração Contemporânea, v. 12, n. 2, p. 533-554, 2008.

MACIAS-CHAPULA, C. A. O papel da informetria e da cienciometria e sua perspectiva nacional e internacional. Ciência da Informação, v. 27, n. 2, p. 134-140, 1998.

MASCARENHAS, A. O.; BARBOSA, A. C. Q. Produção científica brasileira em gestão de pessoas no período 2000-2010. Revista de Administração de Empresas, v. 53, n. 1, p. 35-45, 2013.

MATOS, E. B. S. de; NIYAMA, J. K.; ARAÚJO NETO, L. M. de; MARQUES, M. de M. Congresso ANPCONT: análise bibliométrica descritiva e avaliativa dos artigos publicados de 2007 a 2011. Enfoque: Reflexão Contábil, v. 31, n. 3, p. 73-88, 2012.

MAZZON, J. A.; HERNANDEZ, J. M. da C. Produção científica brasileira em marketing no período 2000-2009. Revista de Administração de Empresas, v. 53, n. 1, p. 67-80, 2013.

MEDEIROS, A. K. de; CRANTSCHANINOV, T. I.; SILVA, F. C. da. Estudos sobre accountability no Brasil: meta-análise de periódicos brasileiros das áreas de administração, administração pública, ciência política e ciências sociais. Revista de Administração Pública, v. 47, n. 3, p. 745-775, 2013.

MELLO, C. M. de; CRUBELLATE, J. M.; ROSSONI, L. Dinâmica de relacionamento e prováveis respostas estratégic as de programas brasileiros de pós-graduação em administração à avaliação da Capes: proposições institucionais a partir da análise de redes de coautorias. Revista de Administração Contemporânea, v. 14, n. 3, p. 434-457, 2010.

MELO, P. L. de R.; ANDREASSI, T. Publicação Científica Nacional e Internacional sobre Franchising: Levantamento e Análise do Período 1998 - 2007. Revista de Administração Contemporânea, v. 14, n. 2, p. 268-288, 2010

MENDES-DA-SILVA, W.; ONUSIC, L. M.; GIGLIO, E. M. Rede de pesquisadores de finanças no Brasil: um mundo pequeno feito por poucos. Revista de Administração Contemporânea, v. 17, n. 6, p. 739-763, 2013.

MENDONÇA NETO, O. R. de; RICCIO, E. L.; SAKATA, C. G. Dez anos de pesquisa contábil no Brasil: análise dos trabalhos apresentados nos ENANPADs de 1996 a 2005. Revista de Administração de Empresas, v. 49, n. 1, p. 62-73, 2009.

MORETTI, S. L. do A.; CAMPANARIO, M. de A. A produção intelectual brasileira em responsabilidade social empresarial RSE sob a ótica da bibliometria. Revista de Administração Contemporânea, v. 13, n. Edição Especial, p. 68-86, 2009.

NARAYANAN, V. K.; ZANE, L. J.; KEMMERER, B. The cognitive perspective in strategy: an integrative review. Journal of Management, v. 37, n. 1, p. 305-351, 2011.

NASCIMENTO, A. R. do; JUNQUEIRA, E.; MARTINS, G. de A. Pesquisa acadêmica em contabilidade gerencial no Brasil: análise e reflexões sobre teorias, metodologias e paradigmas. Revista de Administração Contemporânea, v. 14, n. 6, p. 1113-1133, 2010

NASCIMENTO, S. do; BEUREN, I. M. Redes sociais na produção científica dos programas de pós-graduação de Ciências Contábeis do Brasil. Revista de Administração Contemporânea, v. 15, n. 1, p. 47-66, 2011

NERUR, S. P.; RASHEED, A. A.; NATARAJAN, V. The intellectual structure of the strategic management field: an author cocitation analysis. Strategic Management Journal, v. 29, p. 319-336, 2008.

PATRA, S. K.; BHATTACHARYA, P.; VERMA, N. Bibliometric study of literature on bibliometrics. DESIDOC Bulletin of Information Technology, v. 26, n. 1, p. 27-32, 2006.

PELEIAS, I. R.; CAETANO, G.; PARISI, C.; PEREIRA, A. C. Produção científica sobre controle interno e gestão de riscos no Enanpad e Congresso USP: análise bibliométrica no período 2001-2011. Revista Universo Contábil, v. 9, n. 4, p. 29-49, 2013.

PELEIAS, I. R.; WAHLMANN, G. C.; PARISI, C.; ANTUNES, M. T. P. Dez anos de pesquisa científica em controladoria no Brasil (1997 - 2006). Revista de Administração e Inovação, v. 7, n. 1, p. 193-217, 2010. 
PRITCHARD, A. Statistical bibliography or bibliometrics? Journal of Documentation, v. 25, n. 4, p. 348-349, 1969.

RAMOS-RODRÍGUEZ, A. R.; RUÍZ-NAVARRO, J. Changes in the intellectual structure of strategic management research: a bibliometric study of the strategic management journal, 1980-2000. Strategic Management Journal, v. 25, p. 981-1004, 2004.

RIBEIRO, H. C. M.; COSTA, B. K.; MURITIBA, S. N.; OLIVEIRA NETO, G. C. de. Visão baseada em recursos: uma análise bibliométrica dos últimos 11 anos. Revista de Ciências da Administração, v. 14, n. 34, p. 40-59, 2012.

RIBEIRO, H. C. M.; COSTA, B. K. Brazilian Administration Review: uma análise do perfil da produção acadêmica científica no período de 2004 a 2012 sob a ótica da rede social e da bibliometria. Revista de Ciências da Administração, v. 15, n. 37, p. 65-81, 2013.

RICCIO, E. L.; MENDONÇA NETO, O. R. de; SAKATA, M. C. G. Movimentos de teorias em campos interdisciplinares: a inserção de Michel Foucault na contabilidade. Revista de Administração Contemporânea, v. 11, n. spe, p. 11-32, 2007.

ROBERTSON, C. J. An analysis of 10 years of business ethics research in Strategic Management Journal: 1996-2005. Journal of Business Ethics, v. 80, p. 745-753, 2008.

ROSSONI, L.; GUARIDO FILHO, E. R. Cooperação entre programas de pós-graduação em administração no Brasil: evidências estruturais em quatro áreas temáticas. Revista de Administração Contemporânea, v. 13, n. 3, p. 366-390, 2009.

ROSSONI, L.; HOCAYEN-DA-SILVA, A. J. Administração da informação: a produção científica brasileira entre 2001 e 2006. Revista Eletrônica de Administração, v. 15, n. 2, p. 422-446, 2009.

SARAIVA, E. V.; CARRIERI, A. de P. Citações e não citações na produção acadêmica de estratégia no Brasil: uma reflexão crítica. Revista de Administração da USP, v. 44, n. 2, p. 158-166, 2009.

SHI, W.; SUN, J.; PRESCOTT, J. E. A Temporal perspective of merger and acquisition and strategic alliance initiatives: review and future direction. Journal of Management, 2011.

SOUZA, M. T. S. de; RIBEIRO, H. C. M. Sustentabilidade ambiental: uma meta-análise da produção brasileira em periódicos de administração. Revista de Administração Contemporânea, v. 17, n. 3, p. 368-396, 2013.

TEIXEIRA, J. C.; NASCIMENTO, M. C. R.; ANTONIALLI, L. M. Perfil de estudos em Administração que utilizaram triangulação metodológica: uma análise dos anais do EnANPAD de 2007 a 2011. Revista de Administração da USP, v. 48, n. 4, p. 800812, 2013.

URBIZAGASTEGUI, R. La Bibliometría, Informetría, Cienciometría y otras "Metrías" en el Brasil. Encontros Bibli: Revista Eletrônica de Biblioteconomia e Ciência da Informação, v. 21, n. 47, p. 51-66, 2016.

VALE, G. M. V.; LOPES, H. E. G. Tréplica - riscos e desafios do pesquisador no país das maravilhas: reflexões sobre trajetórias de investigações em alianças estratégicas. Revista de Administração Contemporânea, v. 14, n. 4, p. 752-760, 2010.

VANTI, N. A. P. Da bibliometria à webometria: uma exploração conceitual dos mecanismos utilizados para medir o registro da informação e a difusão do conhecimento. Ciência da Informação, v. 31, n. 2, p. 152-162, 2002.

VANZ, S. A. de S. As redes de colaboração científica no Brasil. Tese (Doutorado em Comunicação e Informação), Faculdade de Biblioteconomia e Comunicação, Porto Alegre, 2009.

WASSERMAN, S.; FAUST, K. Social network analysis: methods and applications. Cambridge: Cambridge University Press, 1994. 


\section{Dados do autor}

Henrique César Melo Ribeiro

Doutor em Administração de Empresas pela Universidade Nove de Julho (Uninove-SP). Professor Adjunto da Universidade Federal do Piauí (UFPI).

hcmribeiro@gmail.com

Recebido - Received: 2016-12-28

Aceitado - Accepted: 2017-12-31

\section{(cc) EY}

This work is licensed under a Creative Commons Attribution 4.0

United States License.

\section{ULLS D-Sorke}

This journal is published by the University Library System of the University of Pittsburgh as part of its

D-Scribe Digital Publishing Program and is cosponsored by the University of Pittsburgh Press. 